\title{
Novel Nanopigment Derived from Vat dyes for Printing Cotton Fabrics
}

\author{
A. Hebeish, M. Rekaby ${ }^{*}$, A.A. Shahin and A.A. Ragheb \\ National Research Centre, Textile Research Division, El-Buhouth \\ St., Dokki, Cairo, Egypt.
}

\begin{abstract}
W ATER insoluble organic pigments presented by vat dyes were $\checkmark$ converted to the soluble leuco form through reduction using different reducing agents. The latter include Glucose, $\beta$-Cyclodextrin, sodium sulfoxylate formaldehyde (Rongalite $\mathrm{C}$ ), and Redoxal $\mathrm{Z}$ reducing agent based on zinc sulfoxylate. The leuco form was then submitted to sudden oxidation using sodium perborate in presence of acetic acid under sonication. The obtained nano-sized pigment particles were used for printing cotton fabrics, and the color strength (K/S) of the prints were monitored. Results disclose that the K/S values for nanopigment prepared under Cyclodextrin reduction are nearly the same, if not higher than those obtained using sulfer-based reducing agents (Rongalate and Redoxal), while Glucose brings about the lowest K/S values. Four vat dyes have been used in the current work, and results of concern verify that the size of nanopigment obtained and the colour strength values $(\mathrm{K} / \mathrm{S})$ are manifestation of nature of the dye including molecular size and structure and molecular configuration. Regardless of the type of reducing agent used and/or the method of fixation, the highest $\mathrm{K} / \mathrm{S}$ values are obtained with nanopigment dispersion prepared using $125 \mathrm{~g} / \mathrm{L}$ reducing agent at $\mathrm{pH}$ 7. Under these conditions, a homogeneous morphology with quite uniform particle size distribution in the range of $6-16 \mathrm{~nm}$ could be achieved vis-á-via 160-280nm for the blank Cibanon Golden Yellow RK vat dye.
\end{abstract}

Keywords: Vat dyes, Nanopigment, Organic Pigments, Pigment rinting, Cyclodextrin and Reducing agent.

Dyes have typically been the colorants of choice for textile printing because they offer superior and brilliant color quality with an expansive color gamut, when compared to conventional pigments. However, dyes are often susceptible to photo-oxidation from light (will lead to poor light fastness), and the ability for the dye to leach into another solvent that makes contact with the printed fabric (will lead to poor water-/solvent-fastness) ${ }^{(1-3)}$.

Pigments may be considered as a better alternative colorants for textile printing since they are insoluble and therefore do not experience colorant diffusion. Pigments can also be significantly less expensive than dyes and can be used in printing all types of fabrics ${ }^{(2-5)}$. Dyestuffs such as sulphur and vat dyes,

*Corresponding author: E-mail: mmrekaby@yahoo.co.uk 
especially indigo, play an important role in today's textile coloration industry (market about one hundred twenty thousand tons per year). Vat dyes are widely used on cellulosic fibres on which they exhibit characteristically excellent light and wet fastness properties ${ }^{(2,6,7)}$.

Vat dyes are insoluble in water. The dyes contain at least two conjugated carbonyl groups which, during their conventional application to cellulosic fibres, are converted by reduction under alkaline conditions to the corresponding, water soluble, 'alkali leuco' form which is applied to the substrate ${ }^{(8-10)}$. At the end, the alkali leuco form is oxidised, so as to regenerate the insoluble parent vat dye in situ within the fiber.<smiles>O=C1c2ccccc2C(=O)c2ccccc21</smiles>

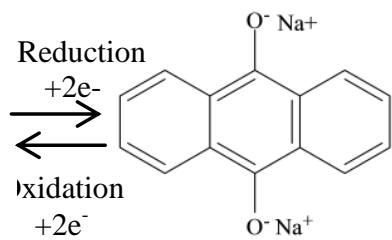<smiles>Oc1c2ccccc2c(O)c2ccccc12</smiles>

Pigment Form Leuco Form Vat Acid Form Water insoluble

In literature ${ }^{(10)}$,the potential of vat dyes as organic pigments have been investigated. Polycyclic, perylenes and perinonones vat dyes, have the physical properties required to convert them into high performance pigments. Indanthrone (Pigment Blue 60), dibromoanthanthrone (Pigment Red 168), and anthrapyrimidine (Pigment Yellow 108), were all used as vat dyes, being Vat Blue 4, Vat Orange 3 and Vat Yellow 20, respectively, before they were used as pigments. However, organic pigments are difficult to be wetted and dispersed in aqueous media due to their low polarity and easy aggregation ${ }^{(11)}$.

Research in nanomaterials has addressed an issue to develop new colorant materials. Such is the case of nanopigments, which emerged as a novel type of pigment, with application mainly in polymeric materials, for coloring the polymer matrix to obtain coatings, however, its applications are growing faster and now it has been used for various types of substrates such as wood, paper, latex, glass, metals and textiles ${ }^{(12)}$. 
The aim of this work is to combine the advantages of both dyes and pigments, converting vat dyes into nanosized organic pigments via sudden oxidation of the leuco form under ultrasonication and its application for textile printing. The nanostructure of the dye and its application via pigment printing technique bring a series of excellent properties: excellent color fastness, good ecological performance and process performance and non-selectivity to various fibers provide a broad market for the product application, and provide a strong technical support to transform the traditional printing and dyeing industry with nanotechnology. Also, this work bring the advantage of the nano-sized organic pigments regarding the fact that they can be considered an ecological alternative to contaminant colorants, in contrast to some traditional inorganic pigments that contained heavy metal in their structure.

\section{Materials}

\section{Experimental}

Substrate

Mill desized, bleached and mercerized cotton fabrics produced by Misr Co. for Spinning and Weaving, El-Mahalla, Egypt.

Thickening agent

Commercial synthetic thickener Daicothick 1600, manufactured by Daico Company, Egypt was used.

Chemicals

Potassium carbonate, glycerine, sodium perborate, sodium carbonate, urea, and acetic acid were of laboratory grade chemicals.

Binder

Binder used is commercial binder named Minex Binder BD supplied by Daico Company, Egypt.

Reducing agents

$-\beta$ - Cyclodextrin and glucose were of laboratory grade chemicals.

-Sodium sulphoxylate formaldehyde (Rongalite C) was kindly supplied by BASF.

-Redoxal $\mathrm{Z}$ reducing agent based on zinc sulfoxylate was kindly supplied by Daico Company, Egypt. 
Dyes used

Common Name

Cibanon Golden Yellow RK

Indanthrene

Orange RK

Farbanthren Blue CLF

\section{C.I. Chemical structure}

Vat Orange 1<smiles>CC1=CC=CC(=c2c(-c3cc(C)ccc3C)ccc3c2=C(C)C(=O)c2ccccc2C3=O)C1=O</smiles>

CAS: 1324-11-4

Supplied by: Ciba, Switzerland

CAS: $1324-11-4$

Supplied by: SigmaAldrich, US

CAS: $2379-79-5$

Supplied by: Atul Ltd, India

CAS: $32220-82-9$

Supplied by: Farbchemie Braun, Germany

\section{Methods}

Preparation of nano-pigment

The particles of vat dyes were changed into nano-pigment via miniaturization of solutions A and B using Ultrasonic homogenizer (SONICS\&MATERIALS, INC), Model: VCX750, Volts: 230VAC 50/60 HZNOM, U.S.A).

A: $40 \mathrm{~g}$. dye, in a total volume of $1000 \mathrm{ml}$, reducing agent (rongalate) $125 \mathrm{~g}$ then the solution was sonicated for $15 \mathrm{~min}$ in presence of non-ionic dispersing agent.

Egypt. J. Chem. 59, No. 1 (2016) 
B: The oxidation bath ( $2 \mathrm{~g}$ sodium perborate and $10 \mathrm{~g} / \mathrm{L}$ acetic acid), added to $\mathrm{A}$ and sonication for $15 \mathrm{~min}$.

Vat dye printing

This is done according to the popular potash / Rongalite process. The following is the recipe which has been employed:

a) Preparation of stock thickener:

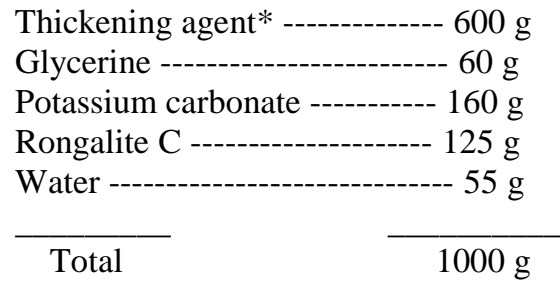

*The thickening agent used was British gum (40\%).

b) Preparation of the printing paste:

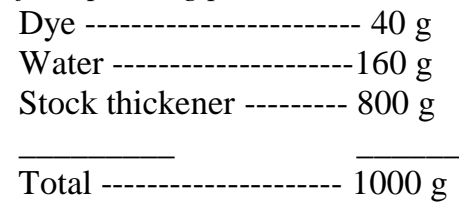

The required amount of dyestuff was pasted with warm water and stirred well to make homogenous suspension paste. The previously prepared stock thickening was added into the paste and mixed thoroughly.

After printing and drying, the printed goods were subjected to fixation via steaming at $120^{\circ} \mathrm{C}$ for $15 \mathrm{~min}$. The printed fabrics were rinsed and oxidized using $2 \mathrm{~g} / \mathrm{L}$ sodium perborate and $10 \mathrm{~g} / \mathrm{L}$ acetic acid (30\%). After oxidation the fabrics were boiled for $5 \mathrm{~min}$ in an aqueous solution containing $2 \mathrm{~g} / \mathrm{l} \mathrm{non-ionic}$ detergent namely Hostapal CV and sodium carbonate $(1 \mathrm{~g} / \mathrm{L})$, and cold water, air dried and assessed for K/S and overall fastness properties measurements.

\section{Washing}

After printing and fixation via microwave irradiation or thermo fixation the printed good were subjected to washing through five stages as follows:

-Rinsing thoroughly with cold water

-Treatment with hot water

-Treatment at the near of boiling temperate with a solution containing $2 \mathrm{~g} / \mathrm{l}$ Aspkon.

-Washing with hot water

-Rinsing with cold water 
-Finally the samples were dried and assessed for colour strength (K/S) measurement.

\section{Characterization}

The nanosized particles and surface morphology of the samples were observed by (TEM) transmission electron microscope (using JEOL JEM-1230 equipment operating at $120 \mathrm{kV}$ with attached CCD camera).

\section{Colour measurements}

The colour strength of the printed samples, expressed as (K/S) and the shade $(\mathrm{L}, \mathrm{a}, \mathrm{b}, \Delta \mathrm{E})$ have been evaluated by reflection spectroscopy with a Hunter lab Ultra Scan PRO spectrophotometer according to a standard method ${ }^{(13)}$.

\section{Results and Discussion}

As already stated, the concept, design and implementation of current innovation are exercised in a such that various factors affecting formation and characterization of nanosized particles derived from vat dyes, are highlighted. Hence, the chemical method advised for preparation of ultrafine (nano) pigment particles is performed under a variety of conditions for the sake of optimization. This method comprises three distinct steps: 1) reduction of the water insoluble vat dye to convert it to the water soluble leuco form, 2) quick and sudden oxidation of this water soluble leuco form of the vat dye under utrasonication, and 3) application of this obtained pigment nanoparticles to printing of cotton fabrics in presence and absence of binder. It is clear, therefore that our work would account for the effects of chemical structure of the vat dye, $\mathrm{pH}$ of the reduction medium, and type and conditions of reducing agent on the colour strength of the prints as elaborated under.

\section{Effect of method of fixation}

Figure 1 shows the TEM image of the blank vat dye and of the obtained nano-pigment dispersion.

As evident, the nanopigment particles analyzed presented a homogeneous morphology with quite uniform particle size distribution as shown in Fig. 1 (b). The particle size diameters obtained were in the range of 20-40nm for the nanopigment (Fig. 1-a) compared to $160-280 \mathrm{~nm}$ for the blank vat dye (Fig. 1-b).

\section{Effect of method of fixation}

Printing pastes prepared using the nano-pigment dispersion of the vat dye Cibanon Golden Yellow RK have been used for printing cotton fabric using pigment printing technique in presence and absence of binder. Another printing paste containing the blank vat dye has been used for printing cotton fabric using the same technique. After printing the fabrics were subjected to fixation via either steaming or thermofixation as described in the experimental part. After washing, and drying, the colour strength values of the printed fabrics are set out in Table 1.

Egypt. J. Chem. 59, No. 1 (2016) 
(a)

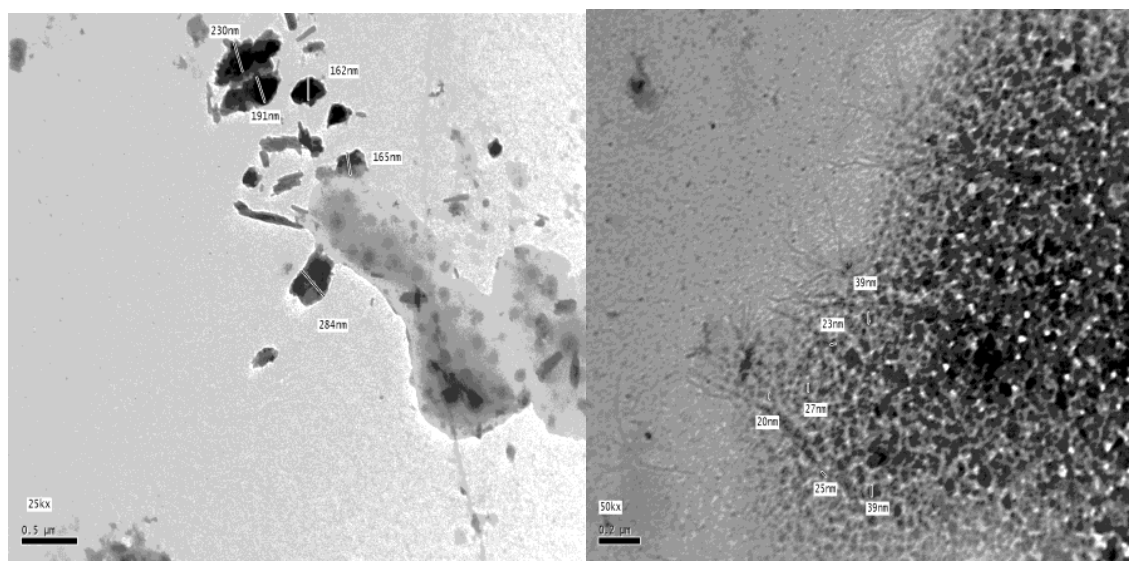

Fig.1. TEM images of Cibanon Golden Yellow RK (a) blank dye, (b) prepared nanopigment emulsion

The data of Table 1 show that the K/S values of the vat dye printed fabrics fixed by steaming is higher than those of fabrics fixed thermally. This is in complete correlation with the conventional method of vat dye printing ${ }^{(2)}$. This is in contrast with the data of the prepared nano-pigment whose K/S values in case of thermofixation is higher than that of steaming. This phenomenon holds true in presence or absence of binder. Nevertheless, the K/S values obtained using binder in pigment printing paste is higher than those obtained without using binder. The K/S of fabrics fixed via thermofixation is 3.25 with binder and 2.65 without binder, compared to 3.10 with binder and 2.27 without binder in case of fixation by steaming. This is also in complete correlation with the conventional method of fixation of pigment printed fabrics ${ }^{(2)}$.

\section{Effect of type of reducing agent}

Until now, in most industrial processes vat dyes (i.e. indigo) are reduced by the conventional, most used reducing agents, sodium dithionite (sodium hydrosulfite), commonly known as hydro or sodium sulphoxylate formaldehyde (Rongalite C), to attain a water soluble form of the dyestuff with affinity to the cellulosic fiber. These reducing agents cannot be recycled. Also, the disposal of rinsing water, containing excess dithionite, sulphite, sulphate, thiosulphate and toxic sulphide is heavily contaminated. These cause high costs and various problems with the effluent (high salt load, depletion of dissolved oxygen, problems with nasal nuisance, toxicity of sulphide, etc.).

In this context, many attempts ${ }^{(8,14,15)}$ have been made to replace the environmentally unfriendly reduction and/or oxidation agents by ecologically more attractive such asreductants (e.g. Cyclodextrin and Glucose). and oxidants (e.g. sodium perborte and sodium persulphate).

Egypt. J. Chem. 59, No. 1 (2016) 
TABLE 1. Effect of the method of fixation on the colour strength values( expressed as $\mathrm{K} / \mathrm{S}$ ) of cotton fabrics printed using nanopigment prepared from Cibanon Golden Yellow RK.

\begin{tabular}{|c|c|c|}
\hline \multirow{2}{*}{ Sample } & \multicolumn{2}{|c|}{ K/S } \\
\cline { 2 - 3 } & Thermofixation & Steaming \\
\hline $\begin{array}{c}\text { Conventional sample } \\
\text { (Vat printing) }\end{array}$ & 2.34 & 2.36 \\
\hline Without Binder & 2.65 & 2.27 \\
\hline Binder & 3.25 & 3.10 \\
\hline
\end{tabular}

Table 2 shows the effect of type of reducing agent on the colouration properties of the fabrics printed using the nanopigment prepared using Rongalate, Redoxal, $\beta$-Cyclodextrin , and glucose as reducing agent.

The data (Table 2) reveal that, the K/S values of the printed fabrics depend on the type of reducing agent used in preparation of the nanopigment dispersion.

In most cases, the $\mathrm{K} / \mathrm{S}$ values obtained for pigment prepared using Cyclodextrin are nearly the same if not higher than those obtained using sulfurbased reducing agents (Rongalate and Redoxal). While Glucose results in the lowest $\mathrm{K} / \mathrm{S}$ values compared to other reducing agents.

This can be explained in terms of the weak reducing properties of glucose and the inclusion cavity of cyclodextrin. The dye molecule in leuco form is easily entrapped in cyclodextrin cavity lowering the molecular aggregation due to intermolecular van der Waals forces, ionic interactions and H-bonds. When these particles are suddenly oxidized to nanopigment ,the particle size will be reserved in the same size and will be more uniform. This is observed in the TEM images of nanopigment dispersions obtained using Cyclodextrin (Fig. 2) where the particles morpholology is homogeneous with particle size in the range of $15-20 \mathrm{~nm}$.

\section{Effect of reducing agent concentration}

The data of Fig. 3 disclose that: regardless of the type of reducing agent used and/or the method of fixation, the highest $\mathrm{K} / \mathrm{S}$ values are obtained using reducing agent concentration of $125 \mathrm{~g} / \mathrm{L}$ in the preparation of nnopigment dispersion. This phenomena holds true with or without using binder in the pigment printing paste.

\section{Effect of pH of nanopigment dispersion}

Figure 4 depicts that the $\mathrm{pH}$ of nanopigment dispersion has a significant effect on the colour strength values of the printed goods. Regardless of the type of reducing agent used and /or the method of fixation employed, the highest K/S values have been obtained for cotton fabrics printed using nanopigment dispersion of $\mathrm{pH} 7$ with or without binder in the printing paste. 
TABLE 2. Effect of type of reducing agent on coloration properties of cotton fabric printed using nanopigment prepared from Cibanon Golden Yellow RK .

\begin{tabular}{|c|c|c|c|c|c|c|c|}
\hline \multicolumn{2}{|c|}{ Type of Reducing Agent } & Fixation & $\mathbf{L}$ & $\mathbf{a}$ & b & $\Delta \mathbf{E}$ & $\mathbf{K} / \mathbf{S}$ \\
\hline \multirow{4}{*}{ Rongalate } & \multirow{2}{*}{$\begin{array}{c}\text { Without } \\
\text { binder }\end{array}$} & Thermofixation & 81.10 & 2.95 & 3.12 & 81.18 & 2.65 \\
\hline & & Steaming & 79.51 & 3.89 & 6.84 & 79.90 & 2.27 \\
\hline & \multirow{2}{*}{$\begin{array}{l}\text { With } \\
\text { binder }\end{array}$} & Thermofixation & 69.75 & 19.07 & 44.09 & 84.70 & 3.25 \\
\hline & & Steaming & 68.02 & 19.55 & 21.63 & 74.0 & 3.10 \\
\hline \multirow{4}{*}{ Redoxal } & \multirow{2}{*}{$\begin{array}{l}\text { Without } \\
\text { binder }\end{array}$} & Thermofixation & 80.56 & 2.32 & 4.52 & 80.72 & 1.54 \\
\hline & & Steaming & 76.32 & 7.60 & 15.07 & 78.17 & 2.42 \\
\hline & \multirow{2}{*}{$\begin{array}{l}\text { With } \\
\text { binder }\end{array}$} & Thermofixation & 69.79 & 19.50 & 45.16 & 85.35 & 3.26 \\
\hline & & Steaming & 65.12 & 20.73 & 20.84 & 71.45 & 3.14 \\
\hline \multirow{4}{*}{ Cyclodextrine } & \multirow{2}{*}{$\begin{array}{l}\text { Without } \\
\text { binder }\end{array}$} & Thermofixation & 75.17 & 9.50 & 29.97 & 81.48 & 1.69 \\
\hline & & Steaming & 72.12 & 14.87 & 37.55 & 82.61 & 3.14 \\
\hline & \multirow{2}{*}{$\begin{array}{c}\text { With } \\
\text { binder }\end{array}$} & Thermofixation & 67.85 & 20.61 & 53.63 & 88.91 & 3.86 \\
\hline & & Steaming & 72.21 & 15.17 & 35.65 & 81.95 & 3.15 \\
\hline \multirow{4}{*}{ Glucose } & \multirow{2}{*}{$\begin{array}{c}\text { Without } \\
\text { binder }\end{array}$} & Thermofixation & 79.81 & 2.60 & 6.91 & 80.15 & 1.44 \\
\hline & & Steaming & 80.29 & 2.53 & 7.14 & 80.65 & 1.81 \\
\hline & \multirow{2}{*}{$\begin{array}{c}\text { With } \\
\text { binder }\end{array}$} & Thermofixation & 69.08 & 17.25 & 46.48 & 85.03 & 3.17 \\
\hline & & Steaming & 72.49 & 13.97 & 32.19 & 80.53 & 3.22 \\
\hline
\end{tabular}

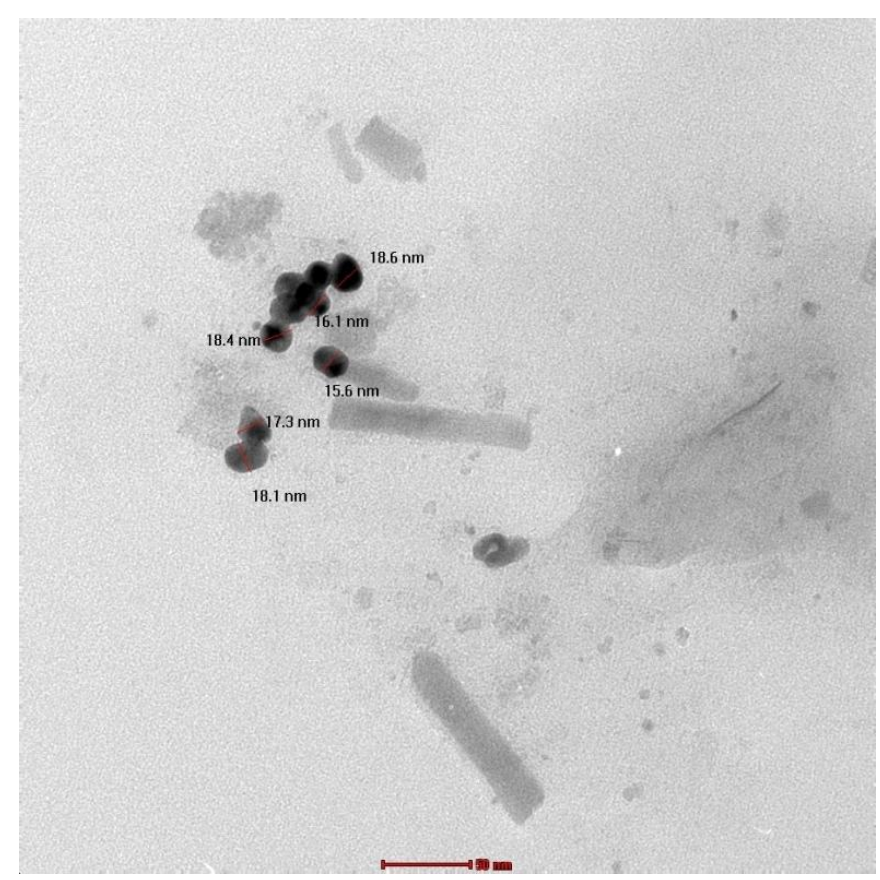

Fig. 2. TEM images of the Cibanon Golden Yellow RK nano-pigment emulsion prepared using Cyclodextrine as a reducing agent . 


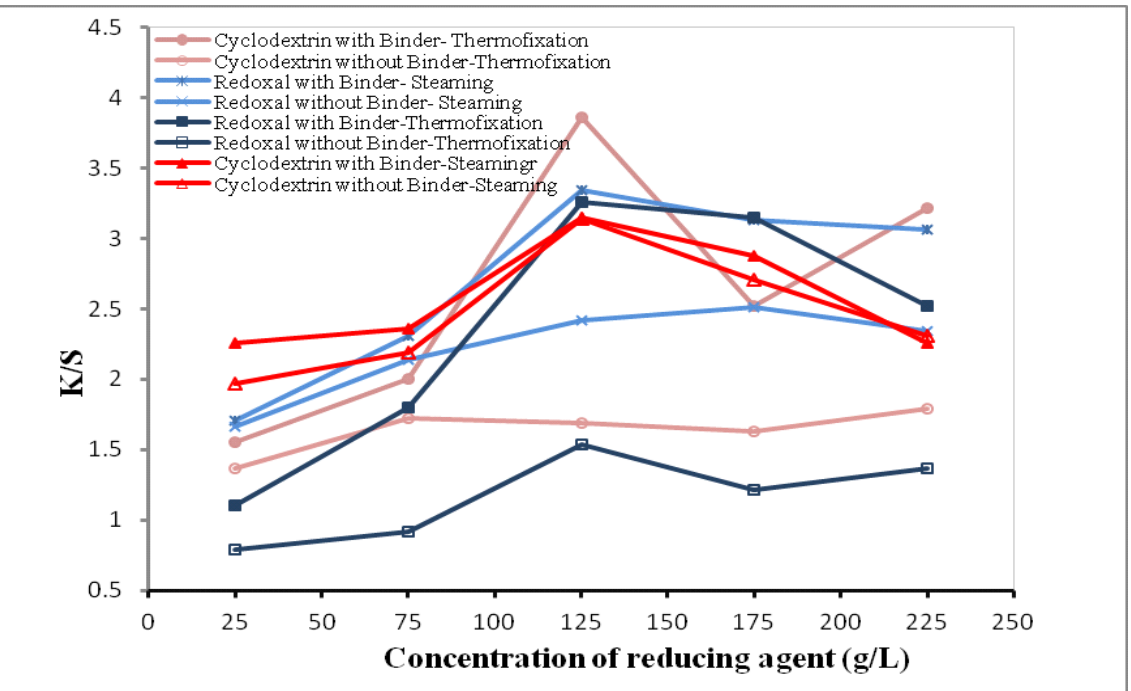

Fig. 3. Effect of concentration of reducing agent used in the preparation of the Cibanon Golden Yellow RK nanopigment dispaersion on the colour strength $(\mathrm{K} / \mathrm{S})$ of the printed cotton fabrics.
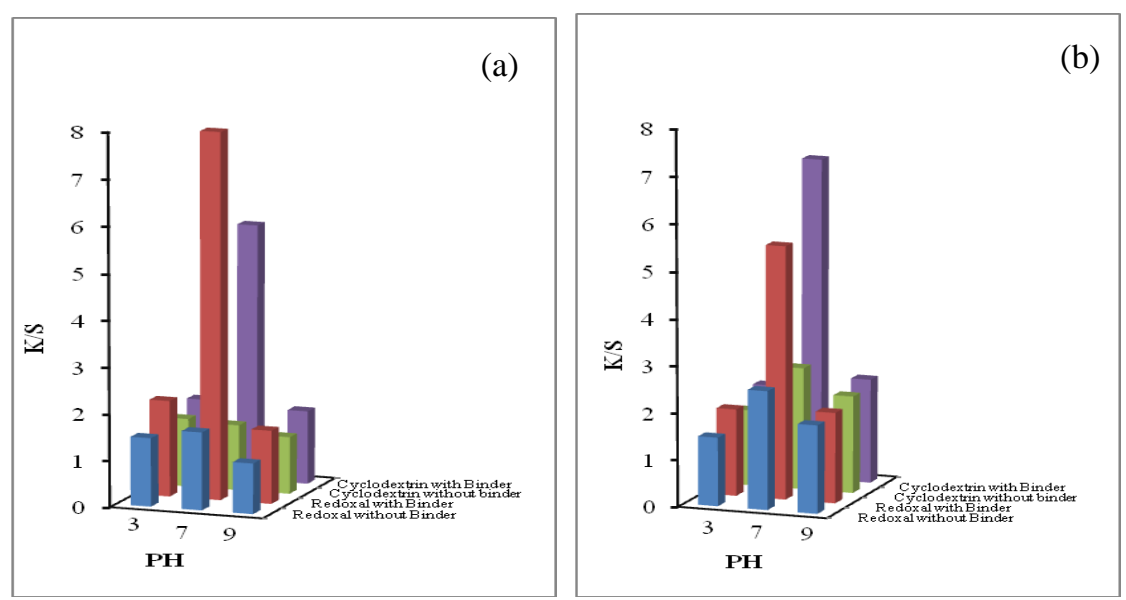

Fig. 4. Effect of $\mathrm{pH}$ of the of the Cibanon Golden Yellow RK nanopigment dispersion on the colour strength $(\mathrm{K} / \mathrm{S})$ of the printed cotton fabrics fixed via (a) Thermofixation, (b) Steaming

The higher colour strength at the $\mathrm{pH} 7$ of the nanopigment dispersion may be attributed to the smaller particle size of the nanopigment obtained.

The TEM images of nanopigment dispersions prepared using either Redoxal or Cyclodextrin are represented in Fig. 5 and 6, respectively.

Egypt. J. Chem. 59, No. 1 (2016) 
The particle size diameters for the nanopigment obtained using Redoxal at $\mathrm{pH} 7$ were in the range of 12-27nm (Fig. 5), and 6-16 nm for nanopigment obtained using Cyclodextrin at $\mathrm{pH} 7$ (Fig. 6) compared to 15-20nm for the nanopigment dispersion previously studied (Fig. 2) and attain this size range at $\mathrm{pH} 9$.

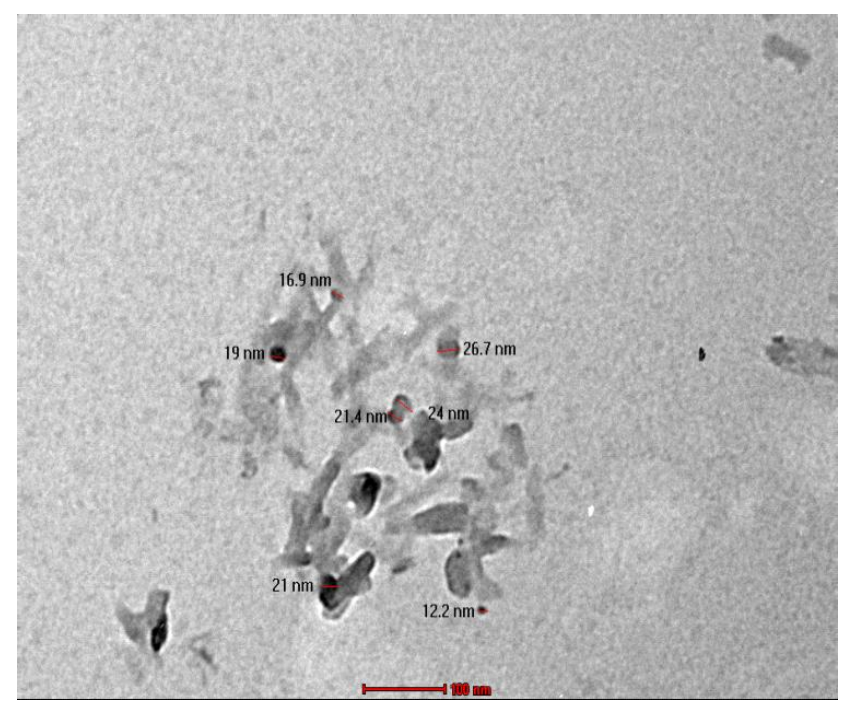

Fig. 5. TEM images of the Cibanon Golden Yellow RK nano-pigment emulsion prepared using Redoxal as a reducing agent with nanopigment dispersion $\mathrm{pH} 7$.

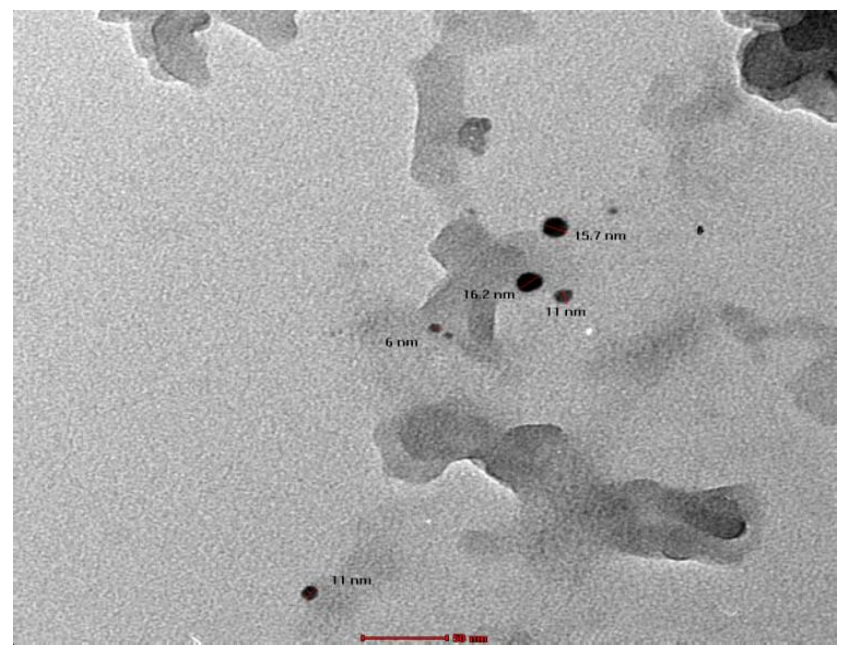

Fig. 6. TEM images of the Cibanon Golden Yellow RK nano-pigment emulsion prepared using Cyclodextrine as a reducing agent with nanopigment dispersion pH 7. 
Effect of dye molecular structure

Vat dyes can be classified in two groups, dyes derived from indigo and dyes derived from anthraquinone ${ }^{(2,8,15)}$. In this work, four vat dyes are used to study the effect of the dye molecular structure on the coloration properties of cotton fabrics printed using the prepared nanopigment dispersion at $\mathrm{pH} 7$ and wih reducing agent concentration of $125 \mathrm{~g} / \mathrm{L}$. Three of the vat dyes used (Cibanon Golden Yellow RK , Indanthrene Orange RK, and Novatic Red 3B) are from the anthraquinone group, and one dye (Farbanthren Blue CLF) from the indigo group. For the sake of comparison, another series of samples have been printed with the blank dyes using conventional vat dye printing recipe and fixation method. The colouration properties of the cotton fabrics printed using blank dye and nanopigment are given in Tables 3 and 4 respectively.

The data of Tables 3 and 4 imply that , regardless of the class of vat dye used; higher colour strength values and different shades are obtained for samples printed with the nanopigment compared to that of the blank vat dye printed samples.

However, the data (Tables 3, and 4), show that the molecular structure of the dye has a great effect on the colour strength of the cotton fabrics printed using either the blank vat dye or its nanopigment dispersion.

TABLE 3. Colouration properties of cotton fabrics printed using the conventional vat dye printing .

\begin{tabular}{|l|c|c|c|c|c|}
\hline Dye Used & L & $\mathbf{a}$ & $\mathbf{b}$ & $\Delta \mathbf{E}$ & $\mathbf{K} / \mathbf{S}$ \\
\hline Cibanon Golden Yellow RK & 67.13 & 23.73 & 50.47 & 87.27 & 2.90 \\
\hline Indanthrene Orange RK & 56.99 & 41.96 & 23.84 & 74.8 & 1.11 \\
\hline Novatic Red 3B & 39.97 & 42.02 & 10.87 & 58.46 & 0.21 \\
\hline Farbanthren Blue CLF & 45.17 & -2.68 & -25.98 & 52.18 & 0.45 \\
\hline
\end{tabular}

Table 4 shows that the K/S values obtained with nanopigment prepared using anthrequinone vat dyes are higher than those obtained with indigo vat dyes. The indigo vat dye, Farbanthren Blue CLF, has the lowest k/S values compared to other vat dyes used. This can be attributed to the more stability of the leuco form of anthraquinone vat dye by virtue of the electronic clouds of aromatic rings.

It has been previously reported in literature ${ }^{(16)}$, that the number of carbonyl groups in the vat dye affect the amount of reducing agent required to obtain the leuco form. This would explain the lower K/S values of the dye Novatic Red 3B which have four carbonyl groups, compared to K/S values for dyes; Cibanon Golden Yellow RK, and Indanthrene Orange RK; which have two carbonyl groups(Tables 3 and 4). With all these dyes ,the same amount of reducing agent was used.

Egypt. J. Chem. 59, No. 1 (2016) 
TABLE 4. Effect of dye molecular structure on coloration properties of cotton fabric printed using nanopigment prepared .

\begin{tabular}{|c|c|c|c|c|c|c|c|c|}
\hline Reducing & \multicolumn{2}{|c|}{ Dye } & \multirow{2}{*}{\begin{tabular}{|l|} 
Fixation \\
Steaming \\
\end{tabular}} & \multirow{2}{*}{$\frac{\mathbf{L}}{68.90}$} & \multirow{2}{*}{$\frac{\mathbf{a}}{17.80}$} & \multirow{2}{*}{$\begin{array}{c}\text { b } \\
33.15\end{array}$} & \multirow{2}{*}{$\frac{\Delta \mathbf{E}}{78.50}$} & \multirow{2}{*}{$\frac{\mathbf{K} / \mathbf{S}}{2.54}$} \\
\hline \multirow{16}{*}{ 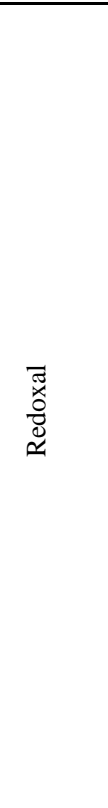 } & \multirow{4}{*}{$\begin{array}{l}\text { Cibanon } \\
\text { Golden } \\
\text { Yellow RK }\end{array}$} & \multirow{2}{*}{$\begin{array}{l}\text { Without } \\
\text { binder }\end{array}$} & & & & & & \\
\hline & & & Thermofixation & 74.84 & 10.48 & 29.86 & 81.26 & 1.68 \\
\hline & & \multirow{2}{*}{$\begin{array}{c}\text { With } \\
\text { binder }\end{array}$} & Steaming & 54.20 & 30.73 & 43.40 & 71.17 & 5.41 \\
\hline & & & Thermofixation & 62.21 & 31.61 & 58.36 & 90.78 & 7.88 \\
\hline & \multirow{4}{*}{$\begin{array}{l}\text { Indanthrene } \\
\text { Orange RK }\end{array}$} & \multirow{2}{*}{$\begin{array}{l}\text { Without } \\
\text { binder }\end{array}$} & Steaming & 67.60 & 27.66 & 12.64 & 74.13 & 1.39 \\
\hline & & & Thermofixation & 63.82 & 34.73 & 18.93 & 75.08 & 1.81 \\
\hline & & \multirow{2}{*}{$\begin{array}{l}\text { With } \\
\text { binder }\end{array}$} & Steaming & 68.26 & 25.25 & 13.89 & 74.09 & 1.24 \\
\hline & & & Thermofixation & 70.37 & 22.34 & 11.79 & 74.77 & 0.96 \\
\hline & \multirow{4}{*}{$\begin{array}{c}\text { Novatic Red } \\
3 \mathrm{~B}\end{array}$} & Without & Steaming & 70.93 & 20.13 & -1.08 & 73.74 & 0.71 \\
\hline & & & Thermofixation & 78.72 & 8.43 & -0.43 & 79.27 & 0.26 \\
\hline & & With & Steaming & 69.57 & 20.12 & 0.24 & 72.43 & 0.79 \\
\hline & & & Thermofixation & 77.07 & 10.39 & -0.29 & 77.78 & 0.32 \\
\hline & \multirow{4}{*}{$\begin{array}{c}\text { Farbanthren } \\
\text { Blue CLF }\end{array}$} & \multirow{2}{*}{$\begin{array}{c}\text { Without } \\
\text { binder }\end{array}$} & Steaming & 65.07 & -2.04 & -12.30 & 66.26 & 0.84 \\
\hline & & & Thermofixation & 63.39 & -3.93 & $\begin{array}{l}-14.78 \\
\end{array}$ & 65.40 & 1.07 \\
\hline & & With & Steaming & 68.63 & -2.10 & -10.79 & 69.51 & 0.62 \\
\hline & & & Thermofixation & 66.31 & -3.04 & $\begin{array}{l}-12.48 \\
\end{array}$ & 67.54 & 0.87 \\
\hline \multirow{16}{*}{ 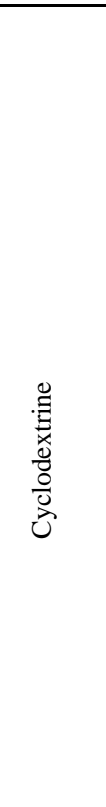 } & \multirow{4}{*}{$\begin{array}{l}\text { Cibanon } \\
\text { Golden } \\
\text { Yellow RK }\end{array}$} & \multirow{2}{*}{$\begin{array}{l}\text { Without } \\
\text { binder }\end{array}$} & Steaming & 72.04 & 14.17 & 36.83 & 82.84 & 2.61 \\
\hline & & & Thermofixation & 77.60 & 6.92 & 22.39 & 81.07 & 1.41 \\
\hline & & With & Steaming & 63.90 & 27.71 & 56.23 & 89.51 & 6.87 \\
\hline & & & Thermofixation & 62.53 & 25.39 & 56.51 & 89.96 & 5.53 \\
\hline & & Without & Steaming & 64.59 & 30.83 & 16.10 & 73.36 & 1.58 \\
\hline & Indantbrene & & Thermofixation & 66.31 & 28.95 & 16.0 & 74.10 & 1.41 \\
\hline & Orange RK & With & Steaming & 68.56 & 25.88 & 11.94 & 74.13 & 1.39 \\
\hline & & & Thermofixation & 67.37 & 29.08 & 15.48 & 74.99 & 1.25 \\
\hline & & Without & Steaming & 74.34 & 13.14 & -0.14 & 75.43 & 0.45 \\
\hline & Novatic Red & & Thermofixation & 77.08 & 10.39 & -0.29 & 77.78 & 0.32 \\
\hline & 3B & $\begin{array}{l}\text { With } \\
\text { binder }\end{array}$ & Steaming & 72.03 & 16.66 & -0.10 & 73.93 & 0.59 \\
\hline & & & Thermofixation & 68.16 & 21.50 & 0.08 & 71.47 & 0.89 \\
\hline & & Without & Steaming & 60.63 & -3.74 & -14.88 & 62.54 & 1.30 \\
\hline & Farbanthren & & Thermofixation & 64.60 & -3.47 & -13.43 & 66.07 & 0.95 \\
\hline & Blue CLF & With & Steaming & 65.09 & -3.98 & -14.02 & 66.70 & 0.94 \\
\hline & & & Thermofixation & 66.91 & -3.95 & -12.93 & 68.26 & 0.81 \\
\hline
\end{tabular}


The k/S and shade obtained with Cibanon Golden Yellow RK, and Indanthrene Orange RK dyes (Tables 3 and 4) indicate that the position of the electron withdrawing group (-Br) with respect to the carbonyl group has an effect on the stability of the dye leuco form. The conjucated position of the (-Br) group with respect to the carbonyl groups in Cibanon Golden Yellow RK results in more stability of the leuco form and hence higher K/S values of the vat dye printed fabrics. Also, this higher stability of the leuco form results in lower particle size of the nanopigment dispersion obtained via sudden oxidation of this leuco form.

Obviously, then, the size of nanopigment obtained is greatly affected by the dye class, and molecular structure of the vat dye .

\section{Conclusion}

-The conversion of several vat dyes into nano-sized organic pigment has been achieved chemically via sudden oxidation of vat dye leuco form obtained using different synthetic or natural reducing agents.

-This study also investigated the use of the prepared nanopigment dispersion in printing cotton fabrics with pigment printing paste in presence or absence of binder using different methods of fixation.

-Higher colour strength values and different shades are obtained with samples printed with the nanopigment compared to that of the blank vat dye printed samples.

-The K/S values obtained in case of thermofixation of cotton fabrics printed using the prepared nanopigment dispersion are nearly the same if not higher than that of steaming.

-In most cases, the K/S values obtained with pigment prepared using Cyclodextrin are nearly the same if not higher than those obtained using sulfurbased reducing agents (Rongalate and Redoxal). While Glucose results in the lowest K/S values compared to other reducing agents.

- Regardless of the type of reducing agent used and/or the method of fixation, the highest $\mathrm{K} / \mathrm{S}$ values are obtained with nanopigment dispersion prepared using $125 \mathrm{~g} / \mathrm{L}$ reducing agent at $\mathrm{pH} 7$.

-The nanopigment particles analyzed presented a homogeneous morphology with quite uniform particle size distribution in the range of 6-16 $\mathrm{nm}$ for the nanopigment prepared using $125 \mathrm{~g} / \mathrm{l}$ cyclodextrin as a reducing agent, at $\mathrm{pH} 7$, compared to $160-280 \mathrm{~nm}$ for the blank vat dye.

- The size of nanopigment obtained and the colour strength values (K/S) are greatly affected by the dye class, and molecular structure of the vat dye .

Egypt. J. Chem. 59, No. 1 (2016) 


\section{References}

1. Fryberg, M., Dyes for ink-jet printing. Rev. Prog. Color, 35, 1-30 (2005).

2. Miles, W.C. Textile Printing, $2^{\text {nd }}$ edition, Society of Dyers and Colorist, Bradford England (2004).

3. Rodriguez,V.M., Gomis, A.M. and Beltran Rico, M.I., Nanoclay-based pigments: synthesis, characterization and application. Nano Product Review Journal, 2 (201304) (2013).

4. Oza, K. and Shah, K., Aqueous system for pigment printing. Textile Dyers and Printers, 21, (11), 21-25 (1988).

5. Poehlmann, A., Pigment printing system. Textile Industries Dyegist, 11 (10), 4-9 (1992).

6. Roessler, A. D., Direct electrochemical reduction of vat dyes in a fixed bed of graphite granules, Crettenand. Dyes and Pigments, 63, 29-37 (2004).

7. Lee, J. Sub Shim, W. Sookim and Ik Kim, J.P., Dyeing and fastness properties of Vat Dye on a Noval Regenerated Cellulosic Fiber. Fibers and Polymers, 6 (3), 244 249 (2005).

8. Teli, M.D., Paul, R., Sachin M. Landage and Aish, A., Ecofriendly processing of sulphur and vat dyes- An overview, IJFTR. 26 (1-2), 101-107 (2001).

9. Burkinshawa, S.M. and Young-A. Son, The dyeing of supermicrofibre nylon with acid and vat dyes. Dyes and Pigments, 87, 132-138 (2010).

10. Thetford, D. and Chorlton, A.P., Investigation of vat dyes as potential high performance pigments. Dyes and Pigments, 61, 49-62 (2004).

11. Zhou, C.L. and Mu, Z.Y., Organic Pigment Chemistry and Technology, China Petrochemical Press, Beijing, (2002).

12. Baena-Murillo, E. and Martínez-Verdú, F., Hybrid Clay/Dye Natural Nanopigment, (NA2COLOR), CREATE Conference, Gjфvik University College, Norway,8th-1 $1^{\text {th }}$ June (2010).

13. Judd. D.B. and Wyszecki, G., Color in Business, Science and Industry, WileyInterscience, 1975.

14. Mojca, B. and Vanja, K., Ecological alternatives to the reduction and oxidation processes in dyeing with vat and sulphur dyes. Dyes and Pigments, 76, 299-309 (2008).

15. Motaghi, Z., The comparison between a natural reducing agent and sodium dithionite in vat, indigo and sulphur dyeing on cotton fabric. Advanced Materials Research, 441, 207-2011 (2012). 
16. Woo S. Shim, Jung J. Lee and Shamey, R., An approach to the influence of particle size distribution of leuco vat dye converted by a reducing agent. Fibers and Polymers, 7(2), 164-168 (2006).

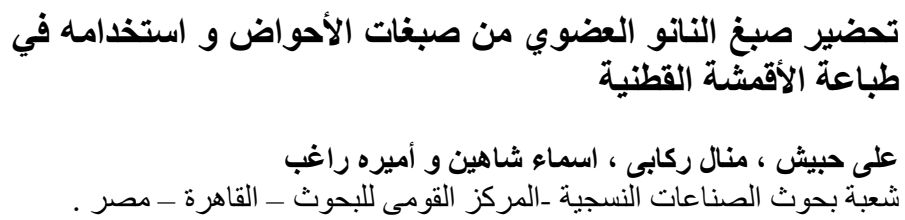

تم في هذا البحث معالجة اربع صبغات عضويه من أصباغ الاحو اض غير الإن القابلة

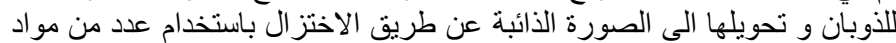

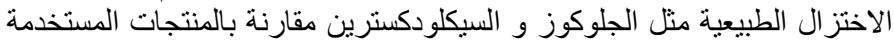

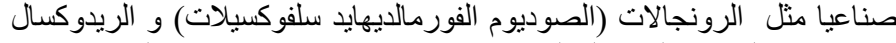

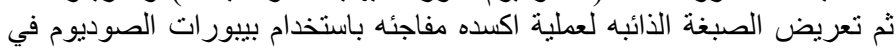

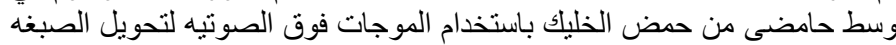
الى بجمنت في حجم النانو.

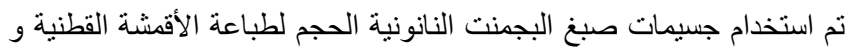

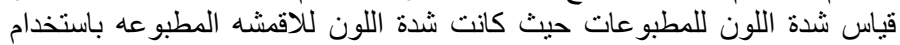

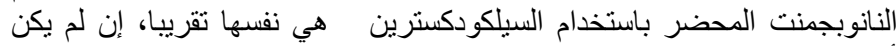

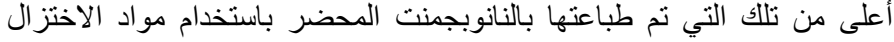

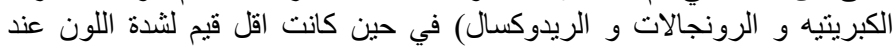
استخدام الجلوكوز في عملية الاختز ال. الروكال.

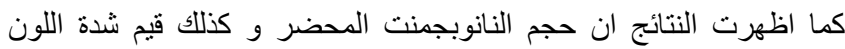

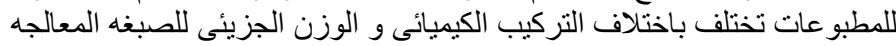

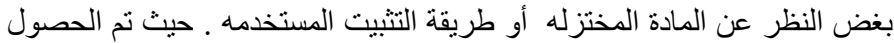

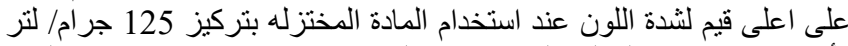

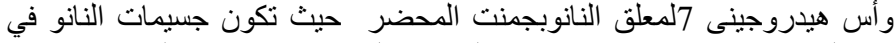

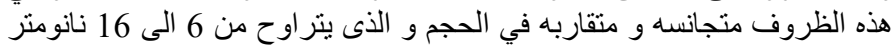

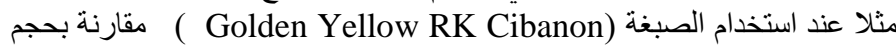
جسيمات الصبغة الغير معالجة و الذى يثر اوح من 160-180 نانومثر . 